\title{
What a Real Argument Is
}

\section{BENJAMIN HAMBY}

\author{
Philosophy Department \\ McMaster University \\ 1280 Main Street West \\ Hamilton, Ontario L8S4S8 \\ Canada \\ hambyb@mcmaster.ca
}

\begin{abstract}
In "What is a 'Real' Argument?" Goddu (2009) suggests and rejects four candidates for what a real argument is, concluding that there is no theoretically significant sub-class of arguments that should be called real. In this paper, contra Goddu, I find that real arguments are arguments that are used or that have prospective use in thinking that aims at reasonable and reflective judgment concerning what to believe or do. Real arguments are therefore the arguments that should be treated in basic reasoning courses, as they are the arguments that students might use outside of the classroom in reallife.
\end{abstract}

\begin{abstract}
Résumé: Dans "What is a 'Real' Argument?" Goddu (2009) suggère et rejette quatre critères pour identifier un argument réel, et conclut qu'il n'y aucune sous-classe théoriquement importante d'argument qu'on devrait appeler réel. Dans cet article contre Goddu, je constate que des arguments réels sont des arguments qui sont utilisés ou qui peuvent être utilisés dans une réflexion qui vise à un jugement raisonnable et réfléchie concernant ce qu'il faut croire ou faire. Des arguments réels sont donc les arguments qu'on doit examiner dans les cours de base de raisonnement, car ils sont les arguments que les élèves pourraient utiliser en dehors de la classe dans la vie de tous les jours.
\end{abstract}

Keywords: Arguments, real, Goddu, critical thinking, pedagogy, prospective usefulness

\section{Introduction}

Nearly all the arguments in this book are arguments which have actually been used by someone with a view to convincing others about some matter. (Fisher 1988: 15, original emphasis)

When we use arguments in the sense of offering reasons for our beliefs, we are responding to controversies by attempting rational persuasion. (Govier 2010: 2, emphasis added)

(C) Benjamin Hamby. Informal Logic, Vol. 32, No. 3 (2012), pp. 313-326. 


\section{Benjamin Hamby}

Logical Self-Defense is [a textbook] that focuses on the interpretation and assessment of 'real-life' arguments. These are the arguments that people formulate and use for practical purposes in their everyday lives. (Johnson and Blair 2006: xix, emphasis added)

In "What is a 'Real' Argument?" (2009) Geoff Goddu provocatively argues that there is no theoretically significant sub-class of arguments that should be called real, challenging the received view by proposing that we abandon talk of real arguments in our theoretical efforts to analyze arguments in general.

In this paper I argue against Goddu's conclusion, finding that real arguments, and the various other words that theorists use to describe them, such as ordinary, everyday, marketplace, real-life, actual, practical, etc., indicate an important theoretical sub-class of arguments, and that we should continue to talk of real arguments, as they serve the important theoretical use of demarcating the arguments that should be studied in a basic reasoning course. In my treatment I frequently cite Fisher (1988), Govier (2010), and Johnson and Blair (2006), authors who I believe exemplify defensible talk of real arguments and equivalent locutions, but who Goddu denies are drawing anything theoretically meaningful by the term. However, to the extent that instruction in argument analysis, evaluation, and construction is warranted in a critical thinking or basic reasoning course, such instruction should focus on real arguments: those that have "prospective usefulness as tools of rational persuasion" (Govier 2010: 2), or that have other prospective uses (Blair, 2004) in efforts to reasonably and reflectively decide what to believe or do (Ennis, 1991). Though I do not seek in this paper to justify Ennis' definition of critical thinking, my interpretation of real arguments borrows language from Ennis' influential conceptualization, whereby critical thinking is defined as "reasonable, reflective thinking that is focused on deciding what to believe or do" (ibid.).

\section{The prospective usefulness of real arguments: A pedagogical rationale}

It is my contention that an argument has prospective usefulness when it could be offered in practice to support a controversial candidate claim that calls for judgment in the context of deciding what to believe or do. Because such claims are entertained by people as legitimate candidates for belief or action, they matter to people substantively: they are the sorts of non-trivial claims a person might genuinely make in some real-life context 
of deciding what to believe or do. As Blair (2004) notes, there are many different uses to which an argument could be put. I have in mind such reflective practices as deliberating to form a judgment regarding the explanatory power of an hypothesis, defending a public policy, deciding how to act when faced with a moral dilemma, or other mundane uses such as deciding which product to buy, which authority to trust, or which charity to donate to, just to cite a few examples.

An important characteristic of real arguments that this interpretation underscores is that they are relevant arguments with conclusions that matter to people in substantive ways. Pedagogues have long recognized that instruction in a basic reasoning course needs to be substantive, and its substance relevant to students in their contextually-laden lives as believers and doers. Textbook writers today, as they did 40 years ago, still attempt to approach informal reasoning instruction from relevant substantial viewpoints in an effort to demonstrate how arguments can be used in practical ways to persuade, justify, inquire, deliberate, resolve conflicts, and in short, to come to reasonable and reflective judgments about what to believe or do. This is not to assert that the instruction of formal logic always of necessity fails to be substantive and relevant: at least some contemporary textbook approaches to formal logic are concerned with real arguments, for example Arthur (2011), who says that his approach deals with "natural arguments, i.e., ones that have been actually offered by historical agents in real-life argumentative contexts" (Arthur 2011: xv). Nor is it to say uncritically that all instructional approaches to informal reasoning fulfill the promise of being relevant to real-life reasoning. It is, however, to indicate the dearth of substantive arguments in approaches to formal logic, and the explicit attempt to include such non-trivial arguments that matter in real-life, in approaches to informal logic.

Indeed, the inspiration for instructors of informal logic is, and has been since authors such as Kahane $(1971)^{1}$ and Scriven (1976) published their trendsetting textbooks, to approach reasoning from a more practically relevant perspective, intending that students will be more willing and more able to connect with the material, employing it in their lives outside of the classroom and in other intellectual pursuits, especially in communicative practice with others. ${ }^{2}$ That has meant, to one degree or another, curbing the amount of formal logic that is introduced: this tactic being inspired in great part by students themselves, who be-

\footnotetext{
${ }^{1}$ A textbook now in its (posthumous) $11^{\text {th }}$ edition: Cavender and Kahane (2010).

${ }^{2}$ For an excellent and original contemporary textbook that exemplifies this, see Bailin and Battersby (2010).
} 


\section{Benjamin Hamby}

moaned how little their formal logic courses offered them in their efforts to think about issues outside of the classroom that mattered to them. This complaint was amplified by the events that were occurring in the world in which Kahane wrote: a cultural uprising that saw a populace increasingly demand accountability from powerful, authoritative social institutions, all the while being bombarded with messages from an ever more manipulative mass-media. The challenge was to devise an introduction to logic that would be relevant to the controversial events and arguments and culture of the day, and the traditional way of teaching formal logic did not seem to fit the bill. These are the roots of the contemporary movement that sees argument as a tool used for reasonableness in real-life, employed in practice to come to more deeply examined beliefs and actions, and it was the absence of these kinds of arguments in formal logic courses that opened the way for theorists to begin to instruct for what they intended to be a more prospectively useful approach to reasoning.

Interestingly, while he makes a passing mention of the pedagogical roots of distinguishing real arguments from other arguments (Goddu 2009: 12), Goddu still denies that there is anything revealing or "theoretically useful" (ibid.) about them. But to the extent that arguments should be examined in a basic reasoning course, it is real arguments that should be the object of that study: arguments that have prospective use as tools of judgment concerning controversial claims about what to believe or do.

I will now proceed by explicating and evaluating Goddu's four candidates for what a real argument is. While there are some positive things to be said for his analysis, I find that none of his candidates as he elucidates them are very plausible, as they fail to do justice to the core motivation behind singling out real arguments as a sub-class of arguments in general. Through my explication of Goddu's paper I will indicate how it is pedagogically illuminating to focus on these sorts of arguments, whether we call them real, ordinary, or practical, or any of the various other ways theorists talk about using arguments as practical tools of judgment, as distinguished from arguments that are not practically useful in contexts that call for judgment about what to believe or do.

\section{Are real arguments genuine arguments?}

Goddu considers what informal logicians might mean by talk of real arguments, positing that they are equivalent to genuine arguments. What is a genuine argument, as opposed to a fake ar- 
gument, or a pseudo argument, or in other words, a not-anargument? This is a theoretically significant question to ask, and one that is debated vigorously, as Goddu points out. Can a judoflip be an argument, as Gilbert (2003) suggests? Is a picture sometimes an argument, as Groarke (2003) claims? What is the difference between an argument and an explanation, as Govier (1987) queries? Does an argument always have a dialectical tier, in addition to an illative core, as Johnson (2000) maintains? Is an argument an abstract object, as Simard-Smith and Moldovan (2011) argue? Are arguments products, the result of a process of arguing, as Goddu (2011) denies?

Goddu (2009) leaves open what a genuine argument is, but he is right to point out both that the question is worth debating, and that it cannot be what is meant by a real argument. What makes an argument an argument is one question (what makes it genuinely an argument as opposed to a non-argument), but by referring to real arguments we do not mean to refer to arguments as arguments per se. Real arguments are a special kind of argument, whatever we decide a genuine argument to be. So by talk of real arguments we are not opposing them to nonarguments, but opposing them to some other kind of argument. Goddu is correct to say that real arguments, whatever they are, belong as members of a proper sub-class of genuine arguments.

\section{Are real arguments never specialized arguments?}

Goddu goes on to consider whether talk of real arguments amounts to talk of "everyday arguments," as opposed to "specialized arguments." I agree with Goddu that real arguments cannot simply be equated with everyday arguments as opposed to specialized arguments. First, Goddu is right to point out that theorists do not always restrict themselves to the "everyday" side of the "rough and ready" distinction between everyday and specialized arguments. But even for those who do talk of everyday arguments, by referring to real arguments this way we should not therefore conclude that theorists mean to exclude specialized arguments.

It is true that theorists who refer to ordinary or everyday arguments appear to distinguish these from specialized arguments. For example, take Govier (2010), who explicitly says that "the arguments we find in newspapers, books, Internet material, and ordinary conversation" (Govier 2010: 2) are the kinds of arguments she introduces in her textbook on practical argumentation. This language, especially talk of "ordinary" conversation, couches the introductory instruction of argumentation in terms that ring of non-specialization. Or take Groarke and Tin- 


\section{Benjamin Hamby}

dale (2008), who say that ordinary arguments "are directed at audiences and constructed with them in mind," and that, in addition to the "specific audience," the "universal audience" should be considered when constructing and evaluating arguments. This mention of the universal audience seems also to couch talk of ordinary arguments in terms of everyday, or non-specialized arguments. However, Fisher (1988), in his approach to a basic reasoning course that showcases real arguments, does not wish to exclude specialized arguments, but gears his approach to using examples of arguments that are sometimes theoretically specialized (many from the disciplinary perspective of philosophy). It is not clear which approach is correct, then: is a real argument one that is ordinary enough so it does not require too much specialized knowledge in order to think about it, or can a real argument be specialized?

While theorists appear to disagree as to whether an everyday argument can be a specialized argument, even if we interpret Govier to be lobbying for an understanding of real arguments as ones that are not specialized (which we need not do, since many of her examples come from specialized disciplinary perspectives, e.g., Govier 2010: 19, 70, 94, 135, 168, 348, and passim. The case is also true for Groarke and Tindale 2008: 51, $174,251,318,390$, and passim.), calling the arguments she lists everyday or ordinary arguments does not necessarily imply that those arguments are not specialized. For the rough and ready distinction between everyday and specialized arguments turns out not to be a very clear distinction at all: there are obviously many books written for the person with specialist knowledge, and presumably the arguments found in them are no less real (no less ordinary or everyday) than any other just by virtue of their having a specialized disciplinary context. This is the case because for the person who is at all familiar with that specialized knowledge, such arguments could very well be ordinary, encountered on an everyday basis. Those books for specialists might not qualify as ordinary if by ordinary one means "written for the layperson," but for that matter, sometimes arguments that are confronted on an everyday basis by laypeople will indeed require some kind of specialized knowledge. This is especially true, for example, concerning the pressing social concerns of our day, such as the global economic crisis, the protracted global war on terrorism, and issues having to do with a person's physical and psychological health. Also, the "ordinary conversation" that occurs between two well-informed and intelligent intellectual peers regarding some complicated subject might well qualify both as an everyday argument (because it would happen in the course of a normal conversation between them), and as a specialized one (because the content of the arguments includes a 
great deal of specialized background knowledge). Finally, a reader might find to be everyday and ordinary the arguments in an op-ed piece in the Financial Times, even though those arguments will be directed towards readers with a certain amount of specialized knowledge, and will be difficult to understand for the person who does not understand economics. For all these reasons, it is difficult to say just how an everyday or ordinary argument must of necessity be non-specialized.

More specialized arguments are not always treated in reasoning texts, not because these are not exemplars of the kinds of arguments that would matter to a layperson in her efforts to think about controversial decisions about what to believe or do (not because they are not real), but because they are too specialized for an introductory class. Such arguments could be considered to be pedagogically unattractive because they require too much knowledge even to get off the ground (complex scientific arguments, for instance, about physical properties of the universe). There might be some good reason not to present in a first year course arguments that are too complex, or ones that require too much specialized background knowledge, but their complexity or specialized disciplinary context does not in principle make them less possible to encounter on an ordinary or everyday basis. Highly specialized content, in other words, does not count against an argument being real. This is especially true when one considers that a major impetus for teaching a basic reasoning course is the hope that transfer will take place, and that students who are introduced to the rudiments of reasoning in the contexts of certain issues will then be able to apply those skills to other situations, ever more complex, that will call for their reasonable and reflective judgment about what to believe or do. So there is nothing about specialized arguments that in principle makes them less real, and if real arguments are everyday arguments, this need not make them unspecialized. These considerations support Goddu's contention that the everyday/specialized distinction cannot be what makes an argument real or not. We need to find some other candidate for real arguments.

\section{Are real arguments practical arguments?}

Goddu goes on to consider what he calls "another version of the everyday/specialized distinction-what is often called the practical/theoretical distinction." (Goddu 2009: 5). Here unfortunately is where I think Goddu's analysis misses the mark, because a practical argument is indeed what we should take a real argument to be, but Goddu uses as his operative distinction be- 


\section{Benjamin Hamby}

tween theory and practice an untenable one, and then claims he has shown real arguments not to be practical ones.

Goddu uses a definition of "practice" that Craig (1996) attributes to Jonsen and Toulmin (1988): "[t]heory employs formal arguments in which particular conclusions are deduced logically from universal principles ... [whereas] [p]ractice, in contrast, employs informal or practical arguments" (Goddu 2009: 5). I agree with Goddu that if this is the distinction we wish to make between theory and practice, it is clear that real arguments are not practical arguments as opposed to theoretical ones. To see why, Goddu corroborates Craig's statement that "Theory is essentially involved in the highly informal argumentative discourses of everyday life, no less than Practice is essentially involved in the most rigorously, formal, scientific disciplines" (Craig 1996: 463). In other words, we cannot exclude from the class of real arguments those that are theoretical (in Jonsen and Toulmin's sense of arguments "in which particular conclusions are deduced logically from universal principles"), because sometimes the arguments we consider in the course of real-life argumentative uses will not be so deduced, and sometimes the practical arguments we consider will be so deduced. Real arguments are therefore not simply practical ones according to this distinction.

But Jonsen and Toulmin's distinction between theory and practice is not the distinction we should operate under when considering arguments in real-life contexts. It is certainly not the one Govier (2010) has in mind when she talks of "practical logic" or when she uses the word "practical" in the title of her book to describe her approach to studying argument. Nor is it the usual distinction we make when speaking of theory as opposed to practice, which usually just distinguishes between the use of something as opposed to the principles that describe it. The idea behind talk of practical argumentation follows this conventional use: the idea of logic that is put into the pragmatic service of being used by someone in real-life and not merely theoretically analyzed apart from its usefulness as a tool of judgment concerning its substantive claims. An argument that was used in practice to argue for some theoretical position would still be a practical argument, then, whether its logic was purely deductive in character, or whether its substantive conclusions were reached in some non-deductive way. This conforms to the practice of teaching informal logic, as well, in that pedagogues like Govier, Johnson and Blair, and Groarke and Tindale have not shied away from including certain basics of deductive logic in their textbooks that teach argument as a practical tool. Govier (2010), for instance, includes chapters on categorical logic and propositional logic in her "practical approach" to 
studying argument. The other authors cited above, in their attempts to introduce real arguments, do likewise. Also, see Hatcher and Spencer (2006), for a deductive reconstructionist approach to critical thinking, wherein arguments that might be used in real-life are subject to deductive analysis before they are evaluated. So real arguments are indeed practical ones, even though they are also sometimes deductive.

In addition, Alec Fisher titles his critical thinking book The Logic of Real Arguments, specifically saying that the focus of his interest is on theoretical reasoning of the kind "that university and college students encounter in the course of their work" (Fisher 1988: vii). Here it is not the everyday/specialized distinction that Fisher operates with when he seeks to instruct people how to think critically by using real arguments, nor is it theoretical (as opposed to practical) arguments, in Jonsen and Toulmin's sense, that he wishes to demarcate. For Fisher specifically says that his "book considers mainly sustained theoretical arguments about the natural world, about society, about policy or about philosophy" (ibid., emphasis added). These theoretical arguments are not opposed to practical ones, as Fisher states when he says he is interested in analyzing the kinds of arguments that people use in argumentative practice to try to establish conclusions: "[n]early all the arguments in this book are arguments which have actually been used by someone with a view to convincing others about some matter" (ibid., p. 15, original emphasis). So we see in Fisher's case that real arguments are not practical as opposed to theoretical arguments, but instead are practical, in that they are or could be used to persuade, even if they regard theoretical claims that are argued in a specialized context.

In essence, Goddu discounts the notion of real arguments being practical arguments by using an implausible operative definition that distinguishes theory from practice in terms of deductive form, taking a cue from Jonsen and Toulmin. But this is the wrong operative definition of the word "practical" to apply to the arguments informal logicians are interested in studying when they talk of real arguments. If we understand a practical argument to be one that is used, which is how the theorists who refer to real arguments talk of them as being practical, in addition to being a standard usage of the word, then this is an illuminating way to distinguish some arguments from others that do not have any use or prospective use in contexts that call for argument as a tool of judgment.

True, as Goddu points out (Goddu 2009: 8), this would still leave us to determine when an argument could have, or could prospectively have, such a use. But this seems not to be such an insurmountable conceptual undertaking, for the argu- 


\section{Benjamin Hamby}

ments that call to be used in efforts to establish their conclusions are those, I contend, whose conclusions are controversial, whose conclusions matter to people in substantive ways, and whose conclusions thus demand support in light of their contestable and substantive claims before they are subscribed to or acted upon. This is why arguments that are meant to merely exemplify do not count as real arguments: their conclusions are usually so inane, so uncontroversial, and matter so little to people in reallife that they require no (real) argument to establish their conclusions in argumentative practice. Take the time honored, but woefully hackneyed example of Socrates' mortality, for example, and how, according to my interpretation, this will never count as a real argument, though valid and sound:

Socrates was a man;

All men are mortal; therefore, Socrates was mortal.

This argument is not real, because it is unlikely that anyone would ever use it to support its uncontroversial conclusion: in other words it would never be used in practice to establish the conclusion as a candidate for belief. It is my position that this is what we should take "practice" and "practical" to mean in the context of talking about the real arguments one should be studying in a critical thinking or informal logic class, or using in reallife. An argument about Socrates' mortality is a poor example of an argument that seeks to persuade, or justify, or establish belief, etc., as it never realistically would be used to establish its trivial and uncontroversial conclusion for any person who entertains it as a candidate belief. So a real argument, as opposed to what Goddu says, is a practical argument, in the sense that it serves or could serve as a tool of persuasion or justification or for some other use in the context of the communicative practice of establishing good candidates for belief and action.

\section{Two more possibilities for what real arguments are}

Goddu considers two more candidates for real arguments, finding that neither is satisfactory. He discounts the idea that real arguments are actual as opposed to hypothetical, and likewise argues against considering real arguments to be natural as opposed to contrived. For the most part I concur with the first of these points. Take his contention that it cannot be that real arguments are actual as opposed to hypothetical. It is true that, as Goddu says, "there are several possibilities and little agreement" (Goddu 2009: 4) as to what the difference between an actual ar- 
gument and a hypothetical argument is. Goddu runs through a few options: an actual argument could be one wherein the premises are asserted rather than supposed, or could be one that has "been made as opposed to ones that merely could be made" (ibid.). Goddu rightly points out that neither of these candidates can be what we mean by real arguments, as many theorists have taken as their object of study arguments that are "missing" premises, and many theorists acknowledge that one might think up any number of arguments that are never (in practice) made. But they would be no less real just because they were never uttered or written. So the actual/hypothetical distinction does not illuminate what we mean by real arguments either.

Still, Goddu's next candidate for what a real argument is does not really strike to the heart of how theorists and pedagogues refer to real arguments. Take Goddu's consideration as to whether a real argument is a natural argument as opposed to a contrived argument. Goddu's analysis here misses the mark because opposing natural arguments to those that are contrived overstates what informal logicians and critical thinking textbook authors mean when they talk of natural arguments that are not contrived. For what theorists mean to indicate by natural arguments are those arguments that are expressed in natural language in communicative practice, and what they mean by arguments that are not contrived are those that are not constructed merely for the sake of illustration, with no substantive content. This is what Fisher means in his book when he says " $[\mathrm{t}]$ he tools of classical logic ... just didn't seem to apply in any straightforward way to the reasoning which students had to read in courses other than logic" (Fisher 1988, p. vii), for in every course other than logic the arguments that are under consideration are expressed not in a formal language but in a natural one, expressed not to exemplify argumentative form but to support a substantive claim. It is also I think what Johnson and Blair meant when they said that they were concerned with the "natural language arguments used in public discourse, clothed in their native ambiguity, vagueness and incompleteness" (Blair and Johnson 1980, p. $\mathrm{x})$. It is not natural as opposed to contrived arguments, per se, that these theorists mean to point out, but natural language arguments (ones that are or could be "used in public discourse" (ibid.)) as opposed to arguments expressed in formalized language (which are almost never used in public discourse), and which, at least in most introductory formal logic classes, are constructed only to exemplify, having little substantive import. This again does not in principle rule out formal logic having any bearing on the reasoning one does in natural language outside of a logic class, but it is to acknowledge the widespread practice of 


\section{Benjamin Hamby}

arguing in natural language that characterizes our attempt to think about what to believe or do.

This is all to say that real arguments cannot be the contrived sort that are used merely to illustrate what an argument's inference looks like, or used merely to investigate argumentative form, or "invented just in order to serve as examples" (Blair and Johnson 1980: 27 n. 20). Such arguments might be contrived, but contrived for some other use (to persuade, to justify, to make a decision, etc.) rather than merely to exemplify. In this way a real argument is a natural argument, as well as a practical one that is used or prospectively used, but while all arguments are in some sense contrived, what matters are the purposes for which they were contrived: if an argument is contrived merely to exemplify an inference, or some other aspect of reasoning, and there is no question as to whether the conclusion or premises, as controversial and substantive claims, should be accepted or not, then the argument is not real.

\section{What a real argument is}

Puzzlingly, I find that while Goddu briefly mentions towards the end of his paper (Goddu 2009: 8) the possible uses of argument to classify them as being real, I also find he does not sufficiently consider this possible candidate for classifying real arguments, to the detriment of his conclusion. Instead, he brushes by this consideration, pointing out that if real arguments are those "that could be reasonably used to convince an audience of something" (ibid), then we still have to determine "what counts as "reasonably used" (ibid.). While this is no doubt true, Goddu passes by the challenge as if he had refuted used arguments as a candidate for real arguments, when what he says no more than points out the challenge. In addition, while Goddu only briefly mentions the pedagogical motivations behind distinguishing real arguments from other arguments, saying that "[p]erhaps appeal to 'real' arguments has some legitimate pedagogical use" (ibid., p. 12), I find this a somewhat empty acknowledgement, as Goddu goes on despite it to say that the notion of real arguments "has no useful theoretical role to play in a general theory of argument" (ibid.). But if there is a legitimate pedagogical use for the distinction, then we should hope that that distinction pulls some theoretical weight, such as indicating the subject matter of informal logic, or indicating the legitimacy or illegitimacy of arguments used as counterexamples in theoretical discussions (ibid.). At the very least, a significant theoretical use of real arguments is to demarcate the sorts of arguments that should be taught in a basic reasoning course. I think real arguments are 
theoretically useful in these ways, and that in our general approach to the theory of argumentation we should recognize the distinction between an argument that has or could have a practical use in a person's effort at reasonably believing and doing, and one that does not or could not.

Furthermore, the majority of the quotes Goddu takes from the scholars whose views he criticizes use the very locution "use" when they describe what they take real arguments to be. This makes Goddu's effort even more puzzling. All of his candidates for what a real argument is are off the mark in that the most explicitly articulated meaning of a real argument is one that is or prospectively could be used as a tool of rational belief, but this is the candidate Goddu examines the least in his effort to unpack what a real argument is.

In sum, arguments that are used in argumentative practice to form beliefs and make decisions, or arguments that could be prospectively used in argumentative practice to such ends, are real arguments, and they are an important sub-class of arguments in general. This is a theoretically illuminating idea because not all arguments are real, in that there will often be instances of genuine arguments that are not used, nor could prospectively be used, to some end of argumentation in the practice of forming beliefs and deciding what to do. If an argument is not real, then it is not the sort of argument we should expose students to in our instructional efforts at helping them to become better and more critical thinkers. What makes an argument useful or prospectively useful is that it is, or could be, offered in support of a candidate claim for belief or action that begs for such support because it is controversial and because it matters to believers and doers. We should therefore continue referring to real arguments, both in our theorizing about arguments in general, and in our practical efforts to instruct for critical thinking.

\section{References}

Arthur, R.T.W. (2011). Natural Deduction: An introduction to logic with real arguments, a little history, and some humor. Peterborough, Ontario: Broadview Press.

Bailin, S., and M. Battersby, (2010). Reason in the Balance: an Inquiry Approach to Critical Thinking. Canada: McGraw-Hill Ryerson.

Blair, J.A. (2004). "Argument and Its Uses." Informal Logic, 24(2): 137-151.

Blair, J.A., and R.H. Johnson (Eds.) (1980). Informal Logic: The First International Symposium. Point Reyes, CA: Edgepress. 
Cavender, N., and H. Kahane (2010). Logic and Contemporary Rhetoric: The use of reason in everyday life ( $11^{\text {th }}$ Edition). Belmont, CA: Wadsworth.

Craig, R.T. (1996). "Practical-Theoretical Argumentation." Argumentation, 10: 461-474.

Ennis, R.H. (1991). "Critical thinking: A streamlined conception." Teaching Philosophy, 14(1), 5-25.

Fisher, A. (1988). The Logic of Real Arguments. Cambridge: Cambridge University Press.

Gilbert, M. (2003). "But why call it an Argument?: In Defense of the Linguistically Inexplicable.” In J.A. Blair, et al. (Eds.), InformalLogic@25: Proceedings of the Windsor Conference. CD-ROM, Windsor, ON: OSSA.

Goddu, G.C. (2009). "What is a 'Real' Argument?" Informal Logic, 29(1): 1-14.

Goddu, G.C. (2011). "Is 'Argument' Subject to the product/process ambiguity?" Informal Logic, 31(2), 75-88.

Govier, T. (1987). "Reasons why Arguments and Explanations are Different." Problems in Argument Analysis and Evaluation. Dordrecht: Foris.

Govier, T. (2010). A Practical Study of Argument ( $7^{\text {th }}$ Edition). Belmont: Wadsworth.

Groarke, L. (2003). "Why do argumentation theorists find it so difficult to recognize visual arguments?" In J.A. Blair, et al. (Eds.), InformalLogic@ 25: Proceedings of the WindsorConference. CD-ROM, Windsor, ON: OSSA.

Groarke, L. and C.W. Tindale, (2008). Good Reasoning Matters! A constructive approach to critical thinking $\left(4^{\text {th }}\right.$ Edition). Don Mills, Ontario: Oxford.

Hatcher, D.L., and L. Anne Spencer (2006). Reasoning and Writing: from critical thinking to composition ( ${ }^{\text {rd }}$ Edition). Boston: American Press.

Johnson, R.H., and J.A. Blair, (2006). Logical Self-Defense. New York: International Debate Education Association.

Johnson, R.H. (2000). Manifest Rationality. Mahwah, NJ: Lawrence Erlbaum and Associates.

Jonsen, A.R. and S. Toulmin (1988). The Abuse of Casuistry: A History of Moral Argument. Berkeley: University of California Press.

Kahane, H., (1971). Logic and Contemporary Rhetoric: The use of reasoning in everyday life. Belmont, CA: Wadsworth.

Scriven, M. (1976). Reasoning. New York: McGraw Hill.

Simard-Smith, P. and A. Moldovan, (2011). Arguments as Abstract Objects. Informal Logic, 31(3): 230-261. 